BMC

Genomics

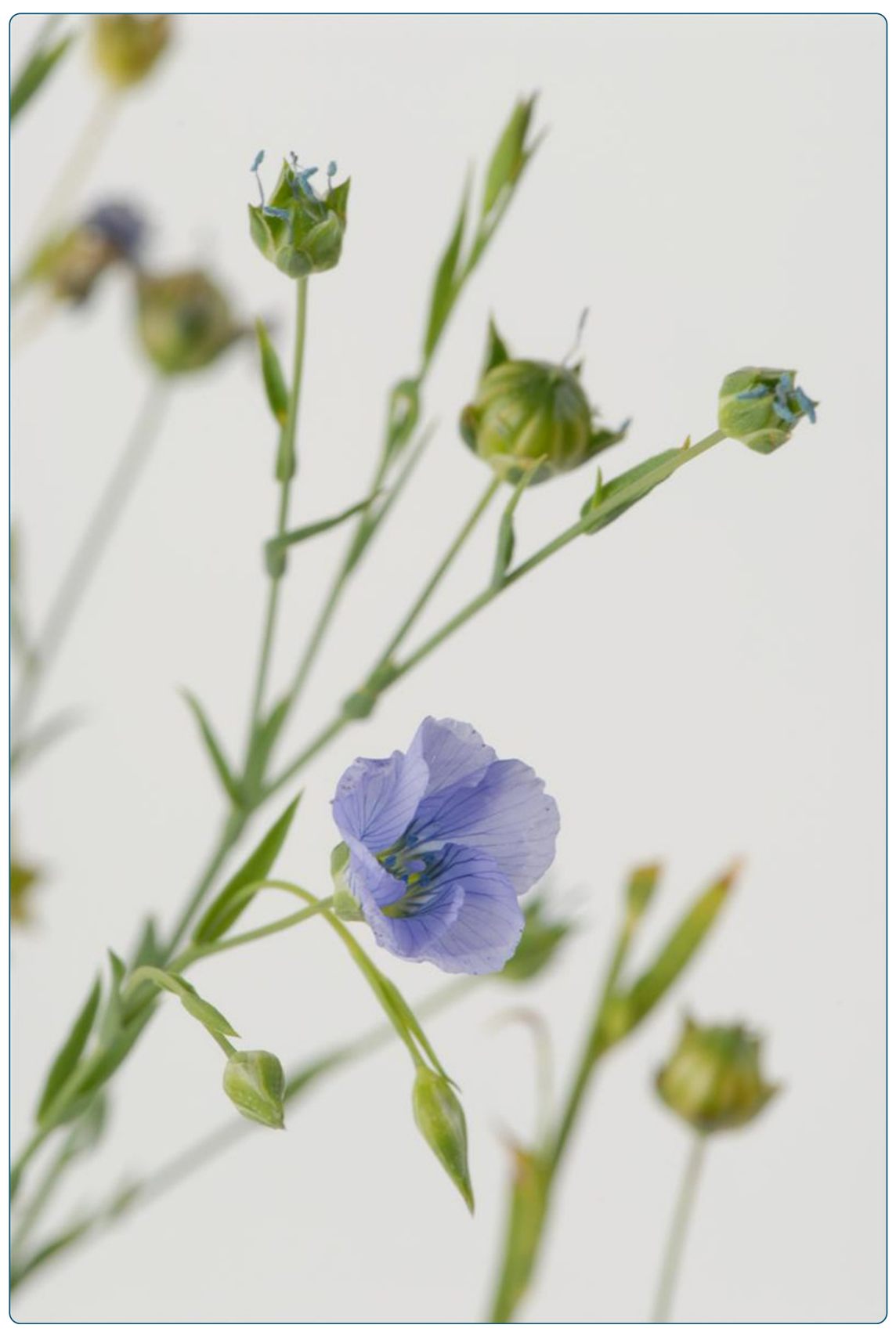

Genome wide SNP discovery in flax through next generation sequencing of reduced representation libraries

Kumar et al. 


\title{
Genome wide SNP discovery in flax through next generation sequencing of reduced representation libraries
}

\author{
Santosh Kumar ${ }^{1,2+}$, Frank M You ${ }^{1+}$ and Sylvie Cloutier ${ }^{1,2^{*}}$
}

\begin{abstract}
Background: Flax (Linum usitatissimum L.) is a significant fibre and oilseed crop. Current flax molecular markers, including isozymes, RAPDs, AFLPs and SSRs are of limited use in the construction of high density linkage maps and for association mapping applications due to factors such as low reproducibility, intense labour requirements and/or limited numbers. We report here on the use of a reduced representation library strategy combined with next generation Illumina sequencing for rapid and large scale discovery of SNPs in eight flax genotypes. SNP discovery was performed through in silico analysis of the sequencing data against the whole genome shotgun sequence assembly of flax genotype CDC Bethune. Genotyping-by-sequencing of an $\mathrm{F}_{6}$-derived recombinant inbred line population provided validation of the SNPs.

Results: Reduced representation libraries of eight flax genotypes were sequenced on the Illumina sequencing platform resulting in sequence coverage ranging from 4.33 to $15.64 \mathrm{X}$ (genome equivalents). Depending on the relatedness of the genotypes and the number and length of the reads, between $78 \%$ and $93 \%$ of the reads mapped onto the CDC Bethune whole genome shotgun sequence assembly. A total of 55,465 SNPs were discovered with the largest number of SNPs belonging to the genotypes with the highest mapping coverage percentage. Approximately $84 \%$ of the SNPs discovered were identified in a single genotype, $13 \%$ were shared between any two genotypes and the remaining $3 \%$ in three or more. Nearly a quarter of the SNPs were found in genic regions. A total of 4,706 out of 4,863 SNPs discovered in Macbeth were validated using genotyping-by-sequencing of $96 \mathrm{~F}_{6}$ individuals from a recombinant inbred line population derived from a cross between CDC Bethune and Macbeth, corresponding to a validation rate of 96.8\%.

Conclusions: Next generation sequencing of reduced representation libraries was successfully implemented for genome-wide SNP discovery from flax. The genotyping-by-sequencing approach proved to be efficient for validation. The SNP resources generated in this work will assist in generating high density maps of flax and facilitate QTL discovery, marker-assisted selection, phylogenetic analyses, association mapping and anchoring of the whole genome shotgun sequence.
\end{abstract}

Keywords: Single nucleotide polymorphism (SNP), Genotyping-by-sequencing (GBS), Reduced representation library (RRL), Illumina, Flax, Linum usitatissimum, AGSNP

\footnotetext{
* Correspondence: sylvie.j.cloutier@agr.gc.ca

†Equal contributors

${ }^{1}$ Cereal Research Centre, Agriculture and Agri-Food Canada, 195 Dafoe Road,

Winnipeg, Manitoba R3T 2M9, Canada

${ }^{2}$ Department of Plant Science, University of Manitoba, 66 Dafoe Road,

Winnipeg, Manitoba R3T 2N2, Canada
}

\section{Biomed Central}

(c) 2012 Kumar et al.; licensee BioMed Central Ltd. This is an Open Access article distributed under the terms of the Creative Commons Attribution License (http://creativecommons.org/licenses/by/2.0), which permits unrestricted use, distribution, and reproduction in any medium, provided the original work is properly cited. 


\section{Background}

Flax (Linum usitatissimum L.) is a self-pollinated annual species $(2 \mathrm{n}=2 \mathrm{x}=30)$ belonging to the Linaceae family. It has been utilised by mankind for some 30,000 years (Paleolithic era) [1], was domesticated $\sim 7,000$ years ago in the Near East and then spread to the Fertile Crescent where it was grown for its seed oil and stem fibres [2]. Currently, Canada is the world's largest producer of linseed (http://publications.gc.ca/collections/collection_2011/ statcan/22-007-X/22-007-2011002-eng.pdf).

Flax oil is highly sought after in the fabrication of biodegradable products such as paint, linoleum and varnish, while its oil-free meal is used as livestock feed. Recently, linseed has gained importance as nutraceutical primarily because of its $\alpha$-linolenic acid (ALA) and lignan content. The ALA component of flax oil (omega-3 fatty acid) improves bone and cardio-vascular health [3-5] while lignans are a rich source of antioxidants and precursors of various hormones [6]. Animal feed for cattle and chicken is being fortified with flax to produce omega-3 enriched meat and eggs [7].

To assess and capitalize upon the genetic variability in flax, genomic resources are needed. The flax genome assembled from short shotgun reads [8] as well as a collection of expressed sequence tags (ESTs) from more than 10 different tissue libraries are now available [9]. Genetic mapping remains a commonly used approach to understand the molecular basis of phenotypic traits. Various molecular markers including random amplified polymorphic DNA (RAPD), restriction fragment length polymorphism (RFLP), amplified fragment length polymorphism (AFLP) and simple sequence repeat (SSR) have been developed to analyse flax genetic diversity [10-19]. Three bi-parental population-based linkage maps of flax have been published to date: an AFLP map of 213 markers [10], an RFLP and RAPD map of 94 markers [12] and an SSR map of 113 markers [18]. A recently constructed 770 SSR consensus map based on three populations constitutes a significant improvement over previous maps but even this marker density remains insufficient for many applications [19]. An ideal molecular approach to generate markers is one that assesses numerous reliable markers covering the entire genome in a single and simple experiment [20]. The discovery of single nucleotide polymorphic (SNP) markers combined with next generation sequencing (NGS) permits the identification of thousands of markers from entire genomes which can be used for linkage map construction, genetic diversity analyses, marker-trait association and marker-assisted selection [21]. SNPs have been discovered by high throughput sequencing in humans [22], Drosophila melanogaster [23], wheat [24], eggplant [25], rice [26-28], Arabidopsis thaliana [29,30], barley [31-33], walnut [34], lupin [35], globe artichoke [36], rapeseed [37], perennial ryegrass [38] and maize [39] to name but a few.
SNP discovery through genome sequencing is readily accomplished in simpler genomes like rice and Arabidopsis $[28,40]$ but the task remains challenging for a number of economically important crops [41,42]. The discovery process is also impeded by the presence of repeat elements, paralogous sequences and reference genomes that are incomplete or inaccurate. The flax genome of CDC Bethune has an estimated size of $\sim 370 \mathrm{Mbp}$ with a high proportion of low copy sequences [43]. Its repetitive fraction consists of ribosomal DNA ( 13.8\%), known transposable elements $(\sim 6.1 \%)$ and putative novel repeat elements $(\sim 7.4 \%)$ [44] making it highly suitable for SNP discovery.

Genomic complexity can be reduced using restriction enzymes [22], high-Cot selection [45], methylation filtration [46], microarrays [47,48] and cDNAs [49]. Trebbi et al. have described the pros and cons of these methods [50]. The use of reduced representation libraries (RRL) is advantageous because the reduction of genome complexity can be altered by selecting different enzymes or size ranges. RRL sequencing, first proposed for the human genome, reduces genome complexity, facilitates re-sampling and generates sufficient coverage for accurate SNP calling [22]. Deep re-sequencing of RRLs using the sequencing-bysynthesis method has been performed for the purpose of SNP discovery in soybean and sorghum $[51,52]$.

SNP genotyping of one to several thousands of SNPs can be performed simultaneously using various chemistries such as Taqman ${ }^{\circledR}$ probes $[53,54]$, Invader ${ }^{\circledR}[55]$, iPLEX $^{\circledR}$ [56], KASPar ${ }^{\text {TM }}$ [57], SNaPshot ${ }^{\text {TM }}$ [58], GoldenGate ${ }^{\circledR}$ [59] and Infinium ${ }^{\circledR}$ assays [60]. The high throughput and constantly decreasing cost of sequencing technologies makes genotyping-by-sequencing (GBS) an attractive choice for genome-wide SNP genotyping.

The objective of the current study was to discover and validate SNPs in flax using a combined NGS of RRLs and GBS strategy with the updated annotation based genomewide SNP discovery pipeline (AGSNP) [34,61]. The resource promises to have several downstream applications including the exploitation of flax genetic diversity through the understanding of important phenotypic traits.

\section{Results}

\section{Selection of genotypes, sequencing and sequence alignment}

Flax genotypes CDC Bethune, Macbeth, SP2047 and UGG5-5 were selected because they are parents of mapping populations. Atlas, Double Low, G-1186/94 and Crepitam Tabor were chosen from a core collection of flax lines because they were genetically diverse according to our previous assessment based on several hundred SSR markers [62]. The broader genetic diversity of these lines minimizes potential biases caused by breeding selection which could decrease the usefulness of SNPs in association mapping [63]. 
All sequencing was performed on the Illumina platform. Advances in sequencing technology through the duration of the project led to reads ranging in length from 50 to $100 \mathrm{bp}$, thus resulting in variation in the number of paired end tag (PET) reads and in sequence coverage among the eight genotypes (Table 1). The data was deposited in the Sort Read Archive of NCBI under accession number SRA061924. The SNP discovery procedure is illustrated in Figure 1.

Bowtie [64] and BWA algorithms [65] were used to map Illumina reads from the eight genotypes to the CDC Bethune whole genome shotgun (WGS) sequence assembly (LinUsi_v1.1, NCBI genome project \#68161) [8], hereafter referred to as the 'reference sequence'. For CDC Bethune Illumina PET reads, the Bowtie algorithm mapped approximately $60.4 \%$ of the reads to the reference sequence, $16.8 \%$ of the reads were supressed due to more than one reported mapping location and $22.8 \%$ of the reads remained unmapped (Additional file 1). Overall, $50.9 \%$ of the reads from the eight genotypes mapped to the reference sequence using Bowtie (Additional file 1). Using BWA, the 34.2 million CDC Bethune reads resulted in 31.8 million mapped reads (93\%) with 2.5 million remaining unmapped (7\%) (Table 1), thus showing the highest percentage of mapped reads as was expected because the reference sequence was obtained from this genotype. Out of 364 million combined reads from the eight genotypes, the BWA algorithm mapped approximately 309 million reads $(84.8 \%)$ and 55 million reads (15\%) remained unmapped (Table 1). The percentage of mapped reads ranged from $\sim 78 \%$ to $93 \%$ depending on the genotypes. The maximum sequence coverage was obtained from G-1186/94 followed by Atlas with 16X and $15 \mathrm{X}$, respectively (Table 1 ).

The distribution of the mapping coverage percentage (MCP) and the mapped read depth (MRD) in bins of 0.5 $\mathrm{Mbp}$ over the entire length of the concatenated reference sequence is shown as heat maps in Figures 2A and 2B, respectively. PET reads from RRL sequences were distributed throughout the concatenated reference sequence, except for the tail end regions that consisted of short sequence contigs less than 200bp in length. A significant positive correlation $\left(\mathrm{R}^{2}=0.78, \mathrm{P}=0.0038^{*}\right)$ between $\mathrm{MCP}$ and sequence coverage was observed (Figure $2 \mathrm{C}$ ). However, the MRD remained relatively unchanged with an increase in sequence coverage, showing no significant correlation between MRD and sequence coverage $\left(R^{2}=0.21, P=0.55 n s\right)$.

\section{SNP discovery and characterization}

The alignment file generated by BWA was used as input for SNP discovery using SAMtools [66]. A total of 71,128 putative SNPs with a quality score $\geq 20$ were identified and processed through the modified AGSNP pipeline [34,61]. After applying the stringent SNP filtering criteria described in Table 2, a total of 55,465 SNPs were retained. The majority of the SNPs ( 90\%) from the seven contrasting genotypes were represented by read depths of $\leq 50$ and $10 \%$ were discovered in regions with total read depths between 51 and 200 (Figure 3A). Sequencing and/or mapping errors (false positives) were estimated by counting the single nucleotide mismatches generated by mapping the CDC Bethune PET reads onto the reference sequence. A false positive rate of $1.9 \times 10^{-5}$ per nucleotide of the

Table 1 Summary of sequencing and read mapping of the Illumina GAllx reads of the reduced representation libraries of eight flax genotypes

\begin{tabular}{|c|c|c|c|c|c|c|c|c|c|c|}
\hline \multirow[t]{2}{*}{ Genotype } & \multirow{2}{*}{$\begin{array}{l}\text { Read } \\
\text { length } \\
\text { (bp) }\end{array}$} & \multicolumn{3}{|c|}{ Total } & \multicolumn{2}{|c|}{ Mapped } & \multicolumn{2}{|c|}{ Unmapped } & \multirow{2}{*}{$\begin{array}{c}\text { Average } \\
\text { mapped } \\
\text { read } \\
\text { depth }^{\mathrm{a}}\end{array}$} & \multirow{2}{*}{$\begin{array}{c}\text { Average } \\
\text { mapping } \\
\text { coverage } \\
(\%)^{b}\end{array}$} \\
\hline & & $\begin{array}{l}\text { Number of } \\
\text { PET reads }\end{array}$ & $\begin{array}{c}\text { Length } \\
\text { (Mbp) }\end{array}$ & $\begin{array}{c}\text { Genome } \\
\text { equivalent }(X)\end{array}$ & $\begin{array}{c}\text { Number of PET } \\
\text { reads }(\%)\end{array}$ & $\begin{array}{c}\text { Length } \\
\text { (Mbp) }\end{array}$ & $\begin{array}{l}\text { Number of } \\
\text { PET reads }\end{array}$ & $\begin{array}{c}\text { Length } \\
\text { (Mbp) }\end{array}$ & & \\
\hline CDC Bethune & 50 & $34,290,788$ & 1,715 & 5 & $31,817,354(93)$ & 1,591 & $2,473,429(7)$ & 124 & 11.20 & 8.83 \\
\hline Macbeth & 50 & $32,815,888$ & 1,641 & 4 & $30,297,145(92)$ & 1,515 & $2,518,739$ (8) & 126 & 7.86 & 13.97 \\
\hline SP2047 & 50 & $35,570,612$ & 1,779 & 5 & $32,667,382(92)$ & 1,633 & $2,903,225(8)$ & 145 & 11.41 & 9.29 \\
\hline UGG5-5 & 50 & $32,046,570$ & 1,602 & 4 & $29,139,577(91)$ & 1,457 & $2,906,989$ (9) & 145 & 10.24 & 8.62 \\
\hline Double Low & 75 & $56,669,792$ & 4,250 & 12 & $47,272,267(83)$ & 3,545 & $9,397,514(17)$ & 705 & 9.28 & 26.65 \\
\hline $\begin{array}{l}\text { Crepitam } \\
\text { Tabor }\end{array}$ & 75 & $57,974,144$ & 4,348 & 12 & $46,740,722(81)$ & 3,506 & $\begin{array}{c}11,233,410 \\
(19)\end{array}$ & 843 & 7.95 & 37.04 \\
\hline G-1186/94 & 100 & $57,867,644$ & 5,787 & 16 & $45,245,067(78)$ & 4,525 & $\begin{array}{c}12,622,561 \\
(22)\end{array}$ & 1,262 & 9.61 & 26.77 \\
\hline Atlas & 100 & $56,900,660$ & 5,690 & 15 & $45,599,045(80)$ & 4,560 & $\begin{array}{c}11,301,600 \\
(20)\end{array}$ & 1,130 & 9.66 & 31.56 \\
\hline Total & & $364,136,098$ & 26,812 & 73 & $308,778,559$ & 22,332 & $55,357,467$ & 4,480 & & \\
\hline
\end{tabular}

Read mapping was performed against the whole genome shotgun sequence assembly (LinUsi_v1.1) of CDC Bethune using BWA.

${ }^{\text {a }}$ Average mapped read depth $(\bar{X})$ was based on a fitted extreme value distribution of mapped read depth in a bin width of $1 \mathrm{Kbp}$ sequence.

${ }^{b}$ The average mapping coverage percentage was estimated based on the CDC Bethune reference genome sequence length of 302 Mbp (size of scaffolds without gaps). 


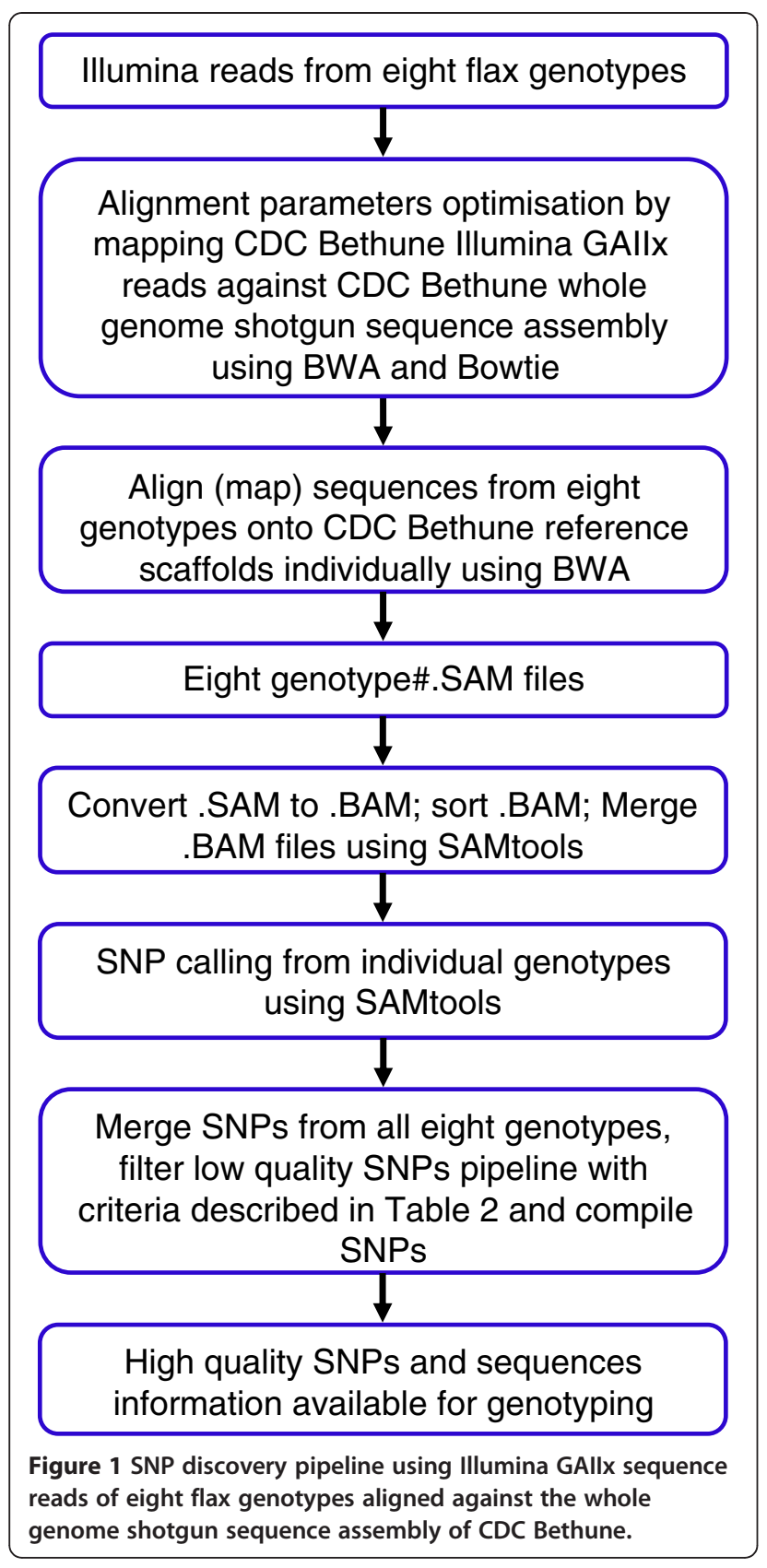

reference sequence (6,072 polymorphic sites/318 Mbp) was obtained using BWA and SAMtools.

The largest number of SNPs was identified from Crepitam Tabor $(21,704)$ followed in decreasing order by Atlas, G-1186/94, Double Low, Macbeth, UGG5-5 and SP2047 (Table 3). The SNP counts and sequence coverage were significantly positively correlated (Figure $3 \mathrm{~B}$ ). Based on the gene prediction database (http://www.phytozome.net/flax) for the reference sequence, we found that a quarter of the SNPs were present in genic regions $(13,367)$, of which $4,515(8 \%)$ were present in the coding regions (Table 3). The average rate of SNP discovery was one SNP per
$34,888 \mathrm{bp}$ for genic regions, one SNP per 11,339 bp for intergenic regions and one SNP per 8,552 bp for the entire genomic regions (data not shown). Close to $84 \%$ of the SNPs $(46,428)$ were detected in a single genotype as compared to the reference sequence with the remaining 16\% $(9,037)$ called in two to seven genotypes (Figure 4A). The distribution of SNPs in bins of $0.5 \mathrm{Mbp}$ showed that the SNPs were distributed throughout the reference genome with the exception of the small contigs as was observed for MCP and MRD (Figure 4B). High SNP density across the genome and spots of very high SNP density can be visualised on the heat maps of Crepitam Tabor and Atlas which had the most SNPs.

Classification of SNPs based on base changes included $36,156(65.2 \%)$ transitions and 19,309 (34.8\%) transversions with a transition to transversion ratio of 1.87 (Additional file 2). An approximately equal number of A/G and $\mathrm{C} / \mathrm{T}$ transitions were observed while $\mathrm{G} / \mathrm{T}$ and $\mathrm{A} / \mathrm{C}$ transversions slightly exceeded $\mathrm{A} / \mathrm{T}$ and $\mathrm{C} / \mathrm{G}$ transversions.

\section{Validation of flax SNPs}

In order to validate the SNPs, we used 5,436 SNPs identified between CDC Bethune and Macbeth (Table 3), and SNP data from the GBS of the $96 \mathrm{~F}_{6}$-derived RILs obtained from a cross between the same two genotypes. The 100bp PET reads of the RILs were mapped to the reference sequence and SNPs called using the same pipeline and criteria (Figure 1, Table 2). A total of 4,863 SNPs out of 5,436 SNP locations were considered for validation because these locations had mapped reads from the individuals of the RIL population that met the criteria for true and false SNPs described below.

SNP locations with reads from 86 or more RILs (90\% of population individuals) that did not show segregation constituted non-validated SNPs. SNP locations with reads from the RIL population that segregated for the SNPs previously identified between CDC Bethune and Macbeth constituted validated SNPs. A total of 4,706 SNPs (96.8\%) were thus validated and 157 SNPs remained non-validated.

\section{Discussion}

The current study was undertaken to discover SNPs using flax genotypes that were parents of mapping populations and/or of diverse genetic backgrounds. The Illumina platform was chosen to sequence the RRLs because of its throughput, relatively low cost, indexing and PET capabilities.

The mapping of sequence reads was performed with Bowtie and BWA using their default settings on the same Linux based servers. Wang and colleagues suggested using Bowtie or BWA for fast and efficient alignment of Illumina short reads [67]. The current study found BWA to be superior to Bowtie at mapping short reads. A higher percentage of read mapping was achieved using BWA (84.8\%) 


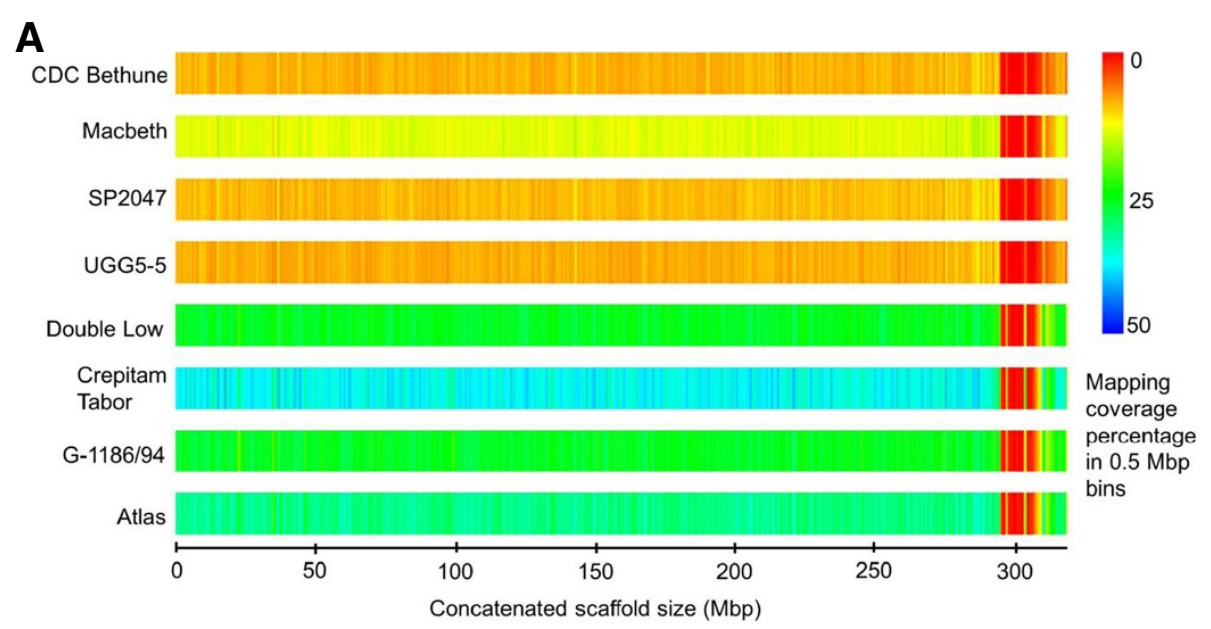

B

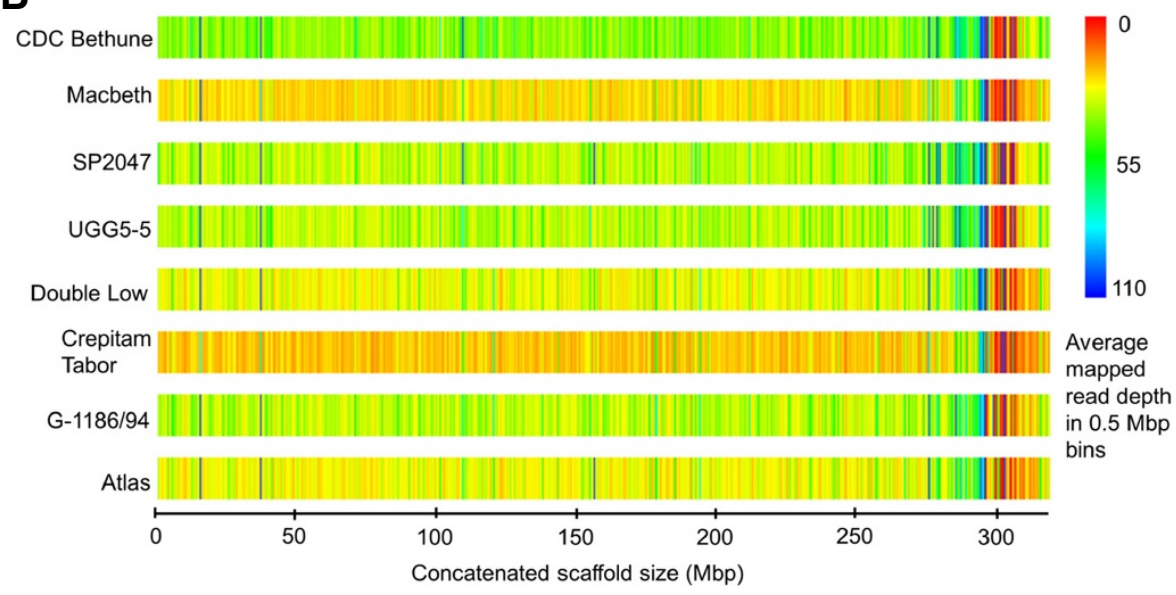

C

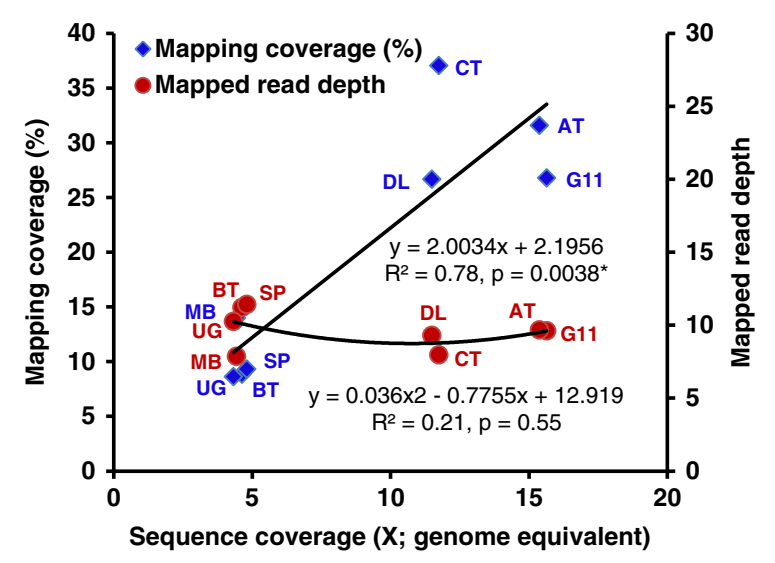

Figure 2 Mapping characteristics of Illumina reads of eight flax genotypes in 0.5 Mbp bins of the concatenated CDC Bethune whole genome shotgun sequence assembly. (A) Heat map distribution of mapping coverage percentage (MCP) and (B) average mapped read depth (MRD). The heat maps were generated using an in-house Java based program. (C) Relationship of sequence genome coverage ( $X$; genome equivalent) with MCP and average MRD (BT-CDC Bethune, MB-Macbeth, SP-SP2047, UG-UGG5-5, DL-Double Low, CT-Crepitam Tabor, G1 1-G-1186/94, AT-Atlas). 
Table 2 SNP filtering criteria for SNP discovery

\begin{tabular}{lc}
\hline Criteria used for SNP calling & Cut-off values \\
\hline Minimum mapped read depth to the reference & $\geq 3$ \\
\hline Maximum mapped read depth to the reference & $\bar{X}+2 s^{a}$ \\
\hline Consensus base ratio & $\geq 0.9$ \\
\hline Mapping quality score in SAMtools & $\geq 20$ \\
\hline Removal of homopolymer SNPs with base string length & $\geq 3 \mathrm{bp}$ \\
\hline $\begin{array}{l}\text { Removal of very close SNPs with gap between } \\
\text { contiguous SNPS }\end{array}$ & $<2 \mathrm{bp}$ \\
\hline $\begin{array}{l}\text { a } \bar{X}+2 s \text { is the average read depth and standard deviation estimated based on } \\
\text { the fitted extreme value distribution for each genotype separately. }\end{array}$
\end{tabular}

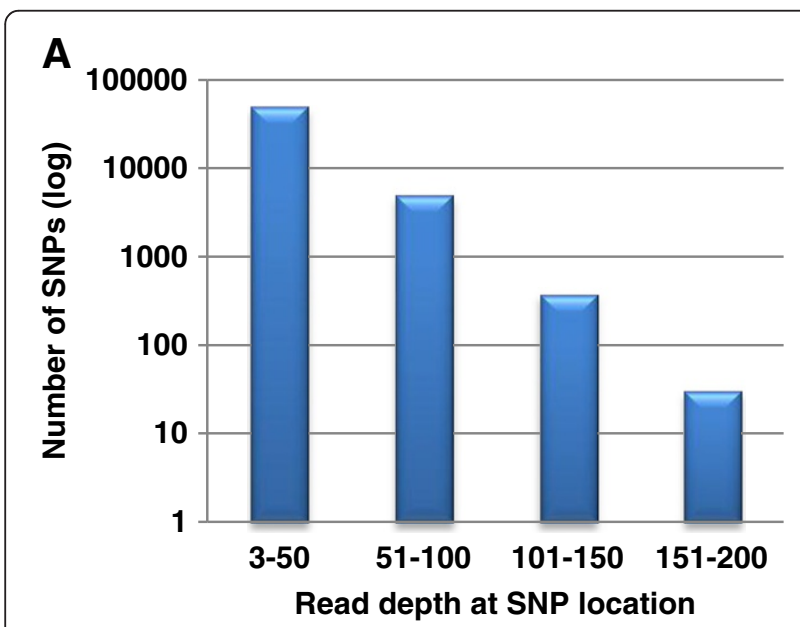

B

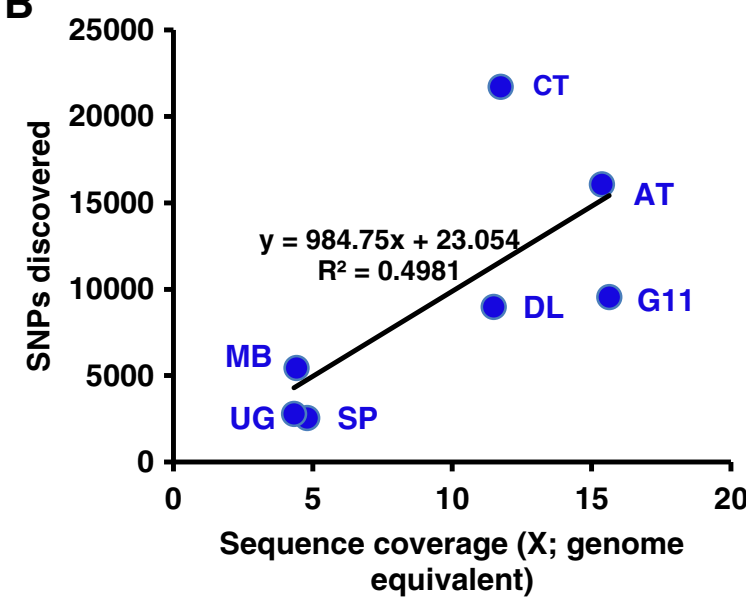

Figure 3 Relationship of SNP discovery with sequence coverage and read depth in seven flax genotypes. (A) Read depth frequency distribution of 55,465 SNP locations identified by alignment of Illumina GAllx reads of seven genotypes against the

CDC Bethune whole genome shotgun sequence assembly.

A minimum of three reads per genotype was required for SNP calling. A log scale was used for the number of SNPs because of the disproportion in the 3-50 reads bin. (B) Correlation of SNP discovery with sequence coverage expressed as genome equivalents (BT-CDC Bethune, MB-Macbeth, SP-SP2047, UG-UGG5-5, DL-Double Low, CT-Crepitam Tabor, G11-G-1186/94, AT-Atlas). compared to Bowtie (62.3\% including the supressed reads) when Illumina reads of eight genotypes were mapped onto the reference sequence (Table 1 and Additional file 1). Since most of the critical parameters between Bowtie and BWA are identical or similar, we hypothesize that the read mapping differences are likely the results of the inability of Bowtie to deal with gapped alignment, a feature incorporated in BWA. The BWA based assembly was chosen for downstream analysis because it produced higher percentages of mapped reads. However, not all but approximately 93\% of the CDC Bethune reads mapped to the reference sequence which is also from CDC Bethune. Inaccuracies in the reference genome assembly, sequencing errors and incomplete reference genome sequences may have contributed to the non- or mis-alignment of reads affecting the mapping percentage [68].

The AGSNP pipeline was initially designed for largescale genome-wide SNP discovery in large and complex genomes using next generation sequences of two homozygous lines [61]. This pipeline was successfully used for SNP discovery between two inbred lines in Aegilops tauschii (genome size of $4.02 \mathrm{Gbp}$ ). Half a million SNPs with a validation rate of $85.9 \%$ were discovered [61]. In the current study, we further updated the pipeline to simultaneously process Illumina reads from eight genotypes. A total of 55,465 SNPs were discovered with sequence data corresponding to coverage of 4.3-15.6X genome equivalents. A SNP validation rate of $96.8 \%$ indicated that the AGSNP pipeline is a high-throughput SNP discovery tool that can be applied to SNP discovery in two or more genotypes from low to high complexity genomes. The updated AGSNP pipeline is available at http://avena.pw.usda.gov/ wheatD/agsnp.shtml.

The RRL approach was successfully adopted in various SNP studies [22,51,69], however, there is little information available regarding the genomic distribution of mapped reads from these studies. Our study demonstrates that the sequencing of RRLs generates reads that were distributed throughout the concatenated reference assembly making these libraries suitable for 'genome-

Table 3 Filtered SNPs identified from eight flax genotypes and their distribution in different genomic regions

\begin{tabular}{lcccc}
\hline Genotype & Identified SNPs & Inter-genic & Genic & CDS \\
\hline Macbeth & 5,436 & 4,065 & 1,371 & 411 \\
\hline SP2047 & 2,530 & 1,942 & 588 & 203 \\
\hline UGG5-5 & 2,759 & 2,042 & 717 & 257 \\
\hline Double Low & 8,951 & 6,793 & 2,158 & 739 \\
\hline Crepitam Tabor & 21,704 & 16,724 & 4,980 & 1,463 \\
\hline G-1186/94 & 9,522 & 7,120 & 2,402 & 955 \\
\hline Atlas & 16,055 & 12,037 & 4,018 & 1,553 \\
\hline
\end{tabular}



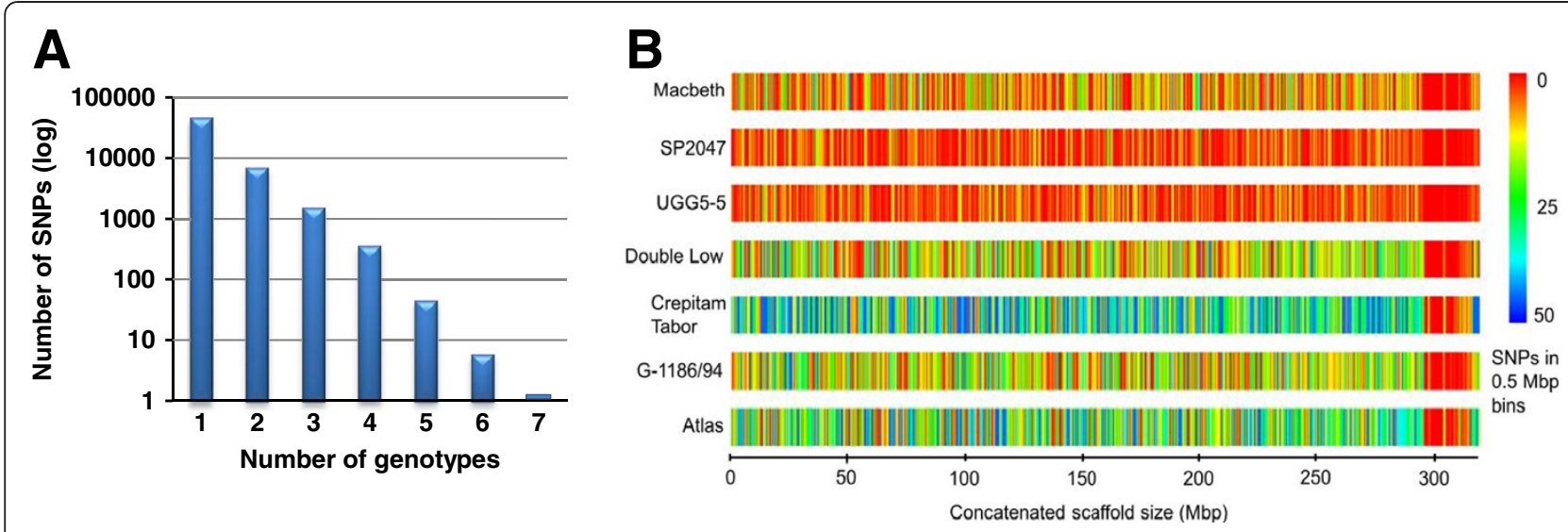

Figure 4 SNP distribution across genotypes. (A) Number of genotypes displaying SNPs compared to the CDC Bethune whole genome shotgun sequence assembly. (B) Heat map showing the distribution of SNPs of the seven flax genotypes along the 0.5 Mbp bins of concatenated whole genome shotgun sequence assembly of CDC Bethune.

wide' SNP discovery and their downstream mapping applications (Figure 2). Increasing the sequence coverage (or number of reads) did not increase the mapped read depth but significantly improved the mapping coverage percentage, eventually resulting in more SNPs discovered (Figures 2 and 3). The lack of sequences pertaining to a specific part of the concatenated assembly may also be due to the exclusion of genomic regions from the restriction digest by MseI. To confirm the genome-wide distribution of the SNPs discovered in our study, we estimated the SNPs distribution in $0.5 \mathrm{Mbp}$ bins and found that the SNPs were well distributed throughout the concatenated reference sequence assembly (Figure 4B).

Advances in next generation sequencing are constantly reducing the cost and increasing both the length and throughput of sequencing to the point where GBS has become possible for a large number of genotypes such as core collections or segregating populations as well as complex genomes. The use of the RRL approach has enhanced read usefulness and assisted in addressing some of the computational challenges for alignment onto a reference sequence.

In our study, 3.2\% (157) of the SNPs could not be validated and were considered false-positive. The false-positive SNPs from non-repetitive regions could result from gene family or duplicate genes which can cause mis-mapping of reads. Validation failure could also be due to errors of the WGS sequence assembly or sequencing errors of the Macbeth reads. By using next generation sequencing, the current study discovered a significant number of flax SNPs with a high validation rate achieved through GBS, which was revealed to be an effective method for large scale SNP validation when used in conjunction with a segregating population. The RRL coupled with GBS approach has been effective in maize, a large genome species of $2.3 \mathrm{Gbp}$, and barley where SNP validation rates of $91 \%$ and $99 \%$ were achieved, respectively [70].
The current study estimated the rate of SNP discovery in flax to be 0.17 SNPs per Kbp across the eight genotypes sequenced. This is lower than potato (11.5 per Kbp) [71], maize (8.9 per Kbp) [72], globe artichoke (5.6 per Kbp) [36], rapeseed (2.2 per Kbp) [37] and grapevine (2.5 per Kbp) [73] but is similar to that found in tomato (0.6 per Kbp) [74] and sweet pepper (1.0 per Kbp) [75]. The lower SNP rate may reflect the low sequence coverage (4-5X) in four of the eight genotypes used or the fact that fewer genotypes were used in the current study compared to other species. The SNP discovery in genic sequences was four fold less than intergenic regions possibly because the intergenic regions evolve faster and accumulate higher polymorphism compared to the conserved genic regions [76]. SNPs from the intergenic regions can, however, also be functional because some non-coding regions harbour regulatory elements like the vegetative to generative transition 1 (vgt1) in maize that are crucial for flowering [77]. In addition, those intergenic SNPs are useful for the construction of high density SNP maps. The high transition/transversion ratio of 1.8 observed in the current study may be an indication of low genetic divergence [78] which can be an outcome of the self-pollinated nature of flax.

\section{Conclusions}

Combined RRL and next generation Illumina sequencing were successfully applied for the large-scale discovery of $\sim 55 \mathrm{~K}$ flax SNPs that were well distributed throughout the genome. The ever decreasing cost of next generation sequencing combined with an ability to index multiple lines per lane enabled validation of a large number of SNPs $(4,706)$ with a validation rate of $96.8 \%$ using GBS of a segregating population, proving this strategy to be powerful for validation purposes. These SNPs will be applied in genetic mapping, anchoring of genetic maps 
with WGS sequence assembly, marker-assisted selection, association mapping and phylogenetic analysis and, as such, they will constitute an important genomic resource for flax studies.

\section{Methods}

\section{Genetic material and DNA isolation}

Eight flax genotypes namely CDC Bethune, Macbeth, SP2047, UGG5-5, Atlas, Double Low, G-1186/94 and Crepitam Tabor were selected. CDC Bethune is a high yielding oilseed flax variety with intermediate oil content, oil quality, seed size and resistance to lodging, rust and fusarium wilt [79]. Macbeth is a medium to late maturing variety that is also lodging resistant and has good yield, high oil content and good oil quality. It is resistant to various forms of rust, fusarium wilt and powdery mildew [80]. SP2047 (Linola ${ }^{\mathrm{TM}}$ 2047) is a yellow-seeded solin line characterized by low linolenic acid (LIN) content (2-4\%) [81] whereas UGG5-5 is a brown-seeded breeding line with higher LIN content (63-66\%) than conventional flax varieties such as CDC Bethune and Macbeth. Double Low is a yellow seeded oilseed breeding line which is low in the two major seed forms of cyanogenic glucosides, namely linustatin and neolinustatin. G-1186/94 is a German yellow seeded oilseed breeding line. Atlas is Swedish flax variety released more than half a century ago [82]. Crepitam Tabor is a Hungarian fibre flax genotype.

The plants were grown in pots in a greenhouse with a 16 $\mathrm{h}$ light and $8 \mathrm{~h}$ dark cycle. DNA was extracted from $10 \mathrm{mg}$ of lyophilised leaf tissue using the Qiagen DNeasy 96 plant kit (Qiagen Sciences, Maryland, USA) according to manufacturer's instructions. A total of $84 \mathrm{bp}$ cutter restriction enzymes were evaluated for their ability to restrict flax genomic DNA. The enzyme MseI was selected because it yielded a large fraction of DNA smaller than the 500bp target size and it generated few high copy number bands in this region. A total of $20 \mu \mathrm{g}$ of DNA of each genotype was restricted with $\mathrm{Mse}$ I (New England Biolabs, Beverly, MA, USA) according to the manufacturer's instructions. The digested DNA was separated on a 1.6\% agarose gel for $6 \mathrm{~h}$ at 100 volts and fragments in the $350-425$ bp size range were excised. This size range was spanned by two high copy number bands that were not included in the excised fraction. Gel extraction of the DNA fraction was done with the QIAEX II gel extraction kit (Qiagen Sciences).

\section{Illumina sequencing}

RRL construction from the 350-425bp fraction and Illumina/Solexa sequencing [83] was performed using Illumina GAIIx sequencing platform (Illumina Inc., San Diego, USA) by the Michael Smith Genome Sciences Centre of the BC Cancer Agency, Genome British Columbia (Vancouver, BC, Canada). Four of the libraries were sequenced as 50bp, 2 as 75bp and 2 as 100bp PET (Table 1).

\section{SNP discovery and characterization}

The WGS sequence assembly of CDC Bethune (http://www. phytozome.net/flax, NCBI genome project \#68161) [8] was used as reference for mapping of all sequence reads. Reads from all eight genotypes including CDC Bethune were aligned using Bowtie (version 0.12.8) and BWA (version 0.6.1) using default settings. An additional parameter to report only the uniquely mapped reads $(m=1)$ was added in Bowtie. The software package SAMtools was used to convert the sequence alignment files from sequence alignment/map (SAM) to sorted binary alignment/map (BAM). The pileup files containing the SNPs were processed through an updated AGSNP pipeline [61] to filter SNPs that had a minimum of three occurrences within any accession. The method is outlined in Figure 1.

Sequence coverage expressed as genome equivalents $(\mathrm{X})$ was calculated by dividing the total read length by the estimated size of the flax genome ( 370 Mbp) $[43,44]$. Mapping coverage percentage $(\mathrm{MCP})$ and mapped read depth (MRD) were used to characterize the sequence coverage and average read mapping depth within a defined interval of the concatenated reference sequence referred to as bins. MCP represents the percentage of the reference sequence (318 Mbp) covered by reads of individual genotypes within a bin size of $0.5 \mathrm{Mbp}$. Similarly, MRD is the average number of mapped reads per mapped position within a bin size of $0.5 \mathrm{Mbp}$ from the individual genotypes mapped separately onto the reference sequence. The heat maps showing MCP, MRD and SNP density were generated using an in-house program written in Java.

In the original AGSNP pipeline [61], the average mapped read depth $(\bar{X})$ was used to identify single copy reference sequences and to set a maximum read depth for filtering paralogous genes or repetitive sequences. Average mapping read depth plus 2 times its standard deviation (s), $\bar{X}+2 s$, was considered to be an optimal cut-off value in the selfpollinating species Aegilops tauschii. We used the same criteria for flax, applying it to each genotype to remove potentially false-positive SNPs due to highly repetitive sequences or mis-mapping. $\bar{X}$ and $s$ were estimated for each genotype based on the mapping results using a pipeline program in the AGSNP package. The SNP filtering criteria are listed in Table 2.

To determine SNP location within genes, we used the gene prediction database available at http://www. phytozome.net/flax that was created using Augustus (version 2.5.5), a Hidden Markov Model-based gene finding program [84] and Glimmer HMM (version 3.0.1) [85].

\section{SNP validation}

GBS was performed on a $96 \mathrm{~F}_{6}$-derived CDC Bethune/ Macbeth RIL population. RRLs were constructed for each RIL and four RILs were indexed per lane of Illumina GAIIx. The 100bp PET reads were mapped onto the CDC Bethune 
reference sequence assembly using the modified AGSNP pipeline and the same parameters as described earlier for the eight genotypes (Table 2). The SNP list generated from the 96 RILs was used to confirm the SNPs initially discovered with the parental accessions. The validation strategy is detailed in the results section of this manuscript.

\section{Additional files}

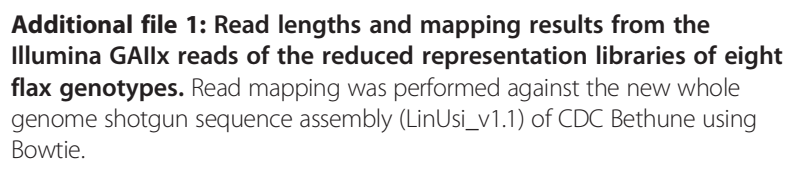

Additional file 2: Transition and transversion frequencies of the 55,465 SNPs.

\section{Competing interests}

The authors declare that they have no competing interests.

\section{Authors' contributions}

SK participated in the design of the study, carried out bioinformatics analysis and wrote the manuscript. FY participated in bioinformatics analysis. SC designed and supervised the study and co-wrote the manuscript. All authors read and approved the final manuscript.

\section{Acknowledgements}

The authors wish to acknowledge the help of Dr. Nick Tinker, Dr. André Laroche and Dallas Thomas for letting us use their computer servers for bioinformatics analysis during the early stages of this study. We thank Nathan King for his input in developing the software for generating heat maps. The authors are grateful to Andrzej Walichnowski for help with manuscript editing, Joanne Schiavoni for formatting and Michael Shillinglaw for figure preparation. This research is part of the Total Utilization Flax GENomic (TUFGEN) project funded by Genome Canada and multiple cofunders. We would like to acknowledge Genome Prairie for management of the project, the province of Manitoba, Flax Council of Canada and Manitoba Flax Growers Association for co-funding specific to this part of the project.

Received: 12 June 2012 Accepted: 29 November 2012 Published: 6 December 2012

\section{References}

1. Kvavadze E, Bar-Yosef O, Belfer-Cohen A, Boaretto E, Jakeli N, Matskevich Z, Meshveliani T: 30,000-year-old wild flax fibers. Science 2009, 325(5946):1359.

2. Zohary D: Monophyletic vs. polyphyletic origin of the crops on which agriculture was founded in the Near East. Genet Resour Crop Evol 1999, 46:133-142.

3. Kim Y, llich JZ: Implications of dietary [alpha]-linolenic acid in bone health. Nutrition 2011, doi:10.1016/j.nut.2011.05.012.

4. West SG, Krick AL, Klein LC, Zhao G, Wojtowicz TF, McGuiness M, Bagshaw DM, Wagner P, Ceballos RM, Holub BJ, Kris-Etherton PM: Effects of diets high in walnuts and flax oil on hemodynamic responses to stress and vascular endothelial function. J Am Coll Nutr 2010, 29(6):595-603.

5. Leyva DR, Zahradka P, Ramjiawan B, Guzman R, Aliani M, Pierce GN: The effect of dietary flaxseed on improving symptoms of cardiovascular disease in patients with peripheral artery disease rationale and design of the FLAX-PAD randomized controlled trial. Contemp Clin Trials 2011, 32(5):724-730.

6. Touré A, Xueming X: Flaxseed lignans: source, biosynthesis, metabolism, antioxidant activity, bio-active components, and health benefits. Comp Rev Food Sci Food Saftey 2010, 9(3):261-269.

7. Woods VB, Fearon AM: Dietary sources of unsaturated fatty acids for animals and their transfer into meat, milk and eggs: A review. Livest Sci 2009, 126(1-3):1-20.
8. Wang Z, Hobson N, Galindo L, Zhu S, Shi D, McDill J, Yang L, Hawkins S, Neutelings G, Datla R, Lambert G, Galbraith DW, Grassa CJ, Geraldes A, Cronk QC, Cullis C, Dash PK, Kumar PA, Cloutier S, Sharpe A, Wong GK, Wang J, Deyholos MK: The genome of flax (Linum usitatissimum) assembled de novo from short shotgun sequence reads. Plant J 2012, doi:10.1111/j.1365-313X.2012.05093.X.

9. Venglat P, Xiang D, Qiu S, Stone SL, Tibiche C, Cram D, Alting-Mees M, Nowak J, Cloutier S, Deyholos M, Bekkaoui F, Sharpe A, Wang E, Rowland G, Selvaraj G, Datla R: Gene expression analysis of flax seed development. BMC Plant Biol 2011, 11:74.

10. Spielmeyer W, Green AG, Bittisnich D, Mendham N, Lagudah ES: Identification of quantitative trait loci contributing to Fusarium wilt resistance on an AFLP linkage map of flax (Linum usitatissimum). Theor Appl Genet 1998, 97(4):633-641.

11. Everaert I, Riek JD, Loose MD, Waes JV, Bockstaele EV: Most similar variety grouping for distinctness evaluation of flax and linseed (Linum usitatissimum L.) varieties by means of AFLP and morphological data. Plant Var Seeds 2001, 14:69-87.

12. Oh TJ, Gorman M, Cullis CA: RFLP and RAPD mapping in flax (Linum usitatisimum). Theor Appl Genet 2000, 101(4):590-593.

13. Stegnil VN, Chudinova Iu V, Salina EA: RAPD analysis of the flax (Linum usitatissimum L.) varieties and hybrids of various productivity. Genetics 2000, 36(10):1370-1373.

14. Fu Y-B, Peterson G, Diederichsen A, Richards KW: RAPD analysis of genetic relationships of seven flax species in the genus Linum L. Genet Resour Crop Evol 2002, 49(3):253-259.

15. Adugna W, Labuschagne MT, Viljoen CD: The use of morphological and AFLP markers in diversity analysis of linseed. Biodivers Consen 2006, 15:3193-3205.

16. Roose-Amsaleg C, Cariou-Pham E, Vautrin D, Tavernier R, Solignac M: Polymorphic microsatellite loci in Linum usitatissimum. Mol Ecol Notes 2006, 6(3):796-799.

17. Cloutier S, Niu Z, Datla R, Duguid S: Development and analysis of EST-SSRs for flax (Linum usitatissimum L.). Theor App/ Genet 2009, 119(1):53-63.

18. Cloutier S, Ragupathy R, Niu Z, Duguid S: SSR-based linkage map of flax (Linum usitatissimum L.) and mapping of QTLs underlying fatty acid composition traits. Mol Breed 2011, 28(4):437-451.

19. Cloutier S, Miranda E, Ragupathy R, Radovanovic N, Reimer E, Walichnowski A, Ward K, Rowland G, Duguid S: Integrated consensus genetic and physical maps of flax (Linum usitatissimum L.). Theor App/ Genet 2012, doi:10.1007/s00122-012-1953-0.

20. Luikart G, England PR, Tallmon D, Jordan S, Taberlet P: The power and promise of population genomics: from genotyping to genome typing. Nat Rev Genet 2003, 4(12):981-994.

21. Cortés A, Chavarro M, Blair M: SNP marker diversity in common bean (Phaseolus vulgaris L.). Theor Appl Genet 2011, 123(5):827-845.

22. Altshuler D, Pollara VJ, Cowles CR, Van Etten WJ, Baldwin J, Linton L, Lander ES: An SNP map of the human genome generated by reduced representation shotgun sequencing. Nature 2000, 407(6803):513-516.

23. Berger J, Suzuki T, Senti K-A, Stubbs J, Schaffner G, Dickson BJ: Genetic mapping with SNP markers in Drosophila. Nat Genet 2001, 29(4):475-481.

24. Allen AM, Barker GL, Berry ST, Coghill JA, Gwilliam R, Kirby S, Robinson P, Brenchley RC, D'Amore R, McKenzie N, Waite D, Hall A, Bevan M, Hall N, Edwards KJ: Transcript-specific, single-nucleotide polymorphism discovery and linkage analysis in hexaploid bread wheat (Triticum aestivum L.). Plant Biotechnol J 2011, 9(9):1086-1099.

25. Barchi L, Lanteri S, Portis E, Acquadro A, Vale G, Toppino L, Rotino G: Identification of SNP and SSR markers in eggplant using RAD tag sequencing. BMC Genomics 2011, 12(1):304.

26. Feltus FA, Wan J, Schulze SR, Estill JC, Jiang N, Paterson AH: An SNP resource for rice genetics and breeding based on subspecies indica and japonica genome alignments. Genome Res 2004, 14(9):1812-1819.

27. McNally KL, Childs KL, Bohnert R, Davidson RM, Zhao K, Ulat VJ, Zeller G, Clark RM, Hoen DR, Bureau TE, Stokowski R, Ballinger DG, Frazer KA, Cox DR, Padhukasahasram B, Bustamante CD, Weigel D, Mackill DJ, Bruskiewich RM, Ratsch G, Buell CR, Leung H, Leach JE: Genomewide SNP variation reveals relationships among landraces and modern varieties of rice. Proc Natl Acad Sci USA 2009, 106(30):12273-12278.

28. Yamamoto T, Nagasaki H, Yonemaru J, Ebana K, Nakajima M, Shibaya T, Yano M: Fine definition of the pedigree haplotypes of closely related rice cultivars by means of genome-wide discovery of single-nucleotide polymorphisms. BMC Genomics 2010, 11:267. 
29. Jander G, Norris SR, Rounsley SD, Bush DF, Levin IM, Last RL: Arabidopsis mapbased cloning in the post-genome era. Plant Physiol 2002, 129(2):440-450.

30. Zhang X, Borevitz JO: Global analysis of allele-specific expression in Arabidopsis thaliana. Genetics 2009, 182(4):943-954.

31. Close TJ, Bhat PR, Lonardi S, Wu Y, Rostoks N, Ramsay L, Druka A, Stein N, Svensson JT, Wanamaker S, Bozdag S, Roose ML, Moscou MJ, Chao S, Varshney RK, Szucs P, Sato K, Hayes PM, Matthews DE, Kleinhofs A Muehlbauer GJ, DeYoung J, Marshall DF, Madishetty K, Fenton RD, Condamine P, Graner A, Waugh R: Development and implementation of high-throughput SNP genotyping in barley. BMC Genomics 2009, 10:582.

32. Waugh $R$, Jannink JL, Muehlbauer GJ, Ramsay L: The emergence of whole genome association scans in barley. Curr Opin Plant Biol 2009, 12(2):218-222.

33. Hayden MJ, Tabone T, Mather DE: Development and assessment of simple PCR markers for SNP genotyping in barley. Theor Appl Genet 2009, 119(5):939-951.

34. You FM, Deal KR, Wang J, Britton MT, Fass JN, Lin D, Dandekar A, Leslie CA, Aradhya M, Luo MC, Dvorak J: Genome-wide SNP discovery in walnut with an AGSNP pipeline updated for SNP discovery in allogamous organisms. BMC Genomics 2012, 13(1):354

35. Yang H, Tao Y, Zheng Z, Li C, Sweetingham M, Howieson J: Application of next-generation sequencing for rapid marker development in molecular plant breeding: a case study on anthracnose disease resistance in Lupinus angustifolius L. BMC Genomics 2012, 13(1):318.

36. Scaglione D, Acquadro A, Portis E, Tirone M, Knapp SJ, Lanteri S: RAD tag sequencing as a source of SNP markers in Cynara cardunculus L. BMC Genomics 2012, 13:3.

37. Bus A, Hecht J, Huettel B, Reinhardt R, Stich B: High-throughput polymorphism detection and genotyping in Brassica napus using nextgeneration RAD sequencing. BMC Genomics 2012, 13(1):281.

38. Pfender WF, Saha MC, Johnson EA, Slabaugh MB: Mapping with RAD (restriction-site associated DNA) markers to rapidly identify QTL for stem rust resistance in Lolium perenne. Theor Appl Genet 2011, 122(8):1467-1480.

39. Jones E, Chu W-C, Ayele M, Ho J, Bruggeman E, Yourstone K, Rafalski A, Smith O, McMullen M, Bezawada C, Warren J, Babayev J, Basu S, Smith S: Development of single nucleotide polymorphism (SNP) markers for use in commercial maize (Zea mays L.) germplasm. Mol Breed 2009, 24(2):165-176.

40. Ossowski S, Schneeberger K, Clark RM, Lanz C, Warthmann N, Weigel D: Sequencing of natural strains of Arabidopsis thaliana with short reads. Genome Res 2008, 18(12):2024-2033.

41. Adams KL, Wendel JF: Polyploidy and genome evolution in plants. Curr Opin Plant Biol 2005, 8(2):135-141.

42. Bennetzen JL, Ma J, Devos KM: Mechanisms of recent genome size variation in flowering plants. Ann Bot 2005, 95(1):127-132.

43. Cullis CA: Mechanisms and control of rapid genomic changes in flax. Ann Bot 2005, 95(1):201-206.

44. Ragupathy $R$, Rathinavelu $R$, Cloutier S: Physical mapping and BAC-end sequence analysis provide initial insights into the flax (Linum usitatissimum L.) genome. BMC Genomics 2011, 12:217.

45. Yuan Y, SanMiguel PJ, Bennetzen JL: High-Cot sequence analysis of the maize genome. Plant J 2003, 34(2):249-255.

46. Palmer LE, Rabinowicz PD, O'Shaughnessy AL, Balija VS, Nascimento LU, Dike S, de la Bastide M, Martienssen RA, McCombie WR: Maize genome sequencing by methylation filtration. Science 2003, 302(5653):2115-2117.

47. Albert TJ, Molla MN, Muzny DM, Nazareth L, Wheeler D, Song X, Richmond TA, Middle CM, Rodesch MJ, Packard CJ, Weinstock GM, Gibbs RA: Direct selection of human genomic loci by microarray hybridization. Nat Methods 2007, 4(11):903-905.

48. Okou DT, Steinberg KM, Middle C, Cutler DJ, Albert TJ, Zwick ME: Microarray-based genomic selection for high-throughput resequencing. Nat Methods 2007, 4(11):907-909.

49. Barbazuk WB, Emrich S, Schnable PS: SNP mining from maize 454 EST sequences. CSH protocols 2007, 2007:pdb prot4786.

50. Trebbi D, Maccaferri M, de Heer P, Sorensen A, Giuliani S, Salvi S, Sanguineti MC, Massi A, van der Vossen EA, Tuberosa R: High-throughput SNP discovery and genotyping in durum wheat (Triticum durum Desf.). Theor Appl Genet 2011, 123(4):555-569.

51. Hyten DL, Cannon SB, Song Q, Weeks N, Fickus EW, Shoemaker RC, Specht JE, Farmer AD, May GD, Cregan PB: High-throughput SNP discovery through deep resequencing of a reduced representation library to anchor and orient scaffolds in the soybean whole genome sequence. BMC Genomics 2010, 11:38.
52. Nelson JC, Wang S, Wu Y, Li X, Antony G, White FF, Yu J: Single-nucleotide polymorphism discovery by high-throughput sequencing in sorghum. BMC Genomics 2011, 12:352.

53. Livak KJ, Rogers J, Lichter JB: Variability of dopamine D4 receptor (DRD4) gene sequence within and among nonhuman primate species. Proc Natl Acad Sci USA 1995, 92(2):427-431

54. Salvi S, Tuberosa R, Phillips RL: Development of PCR-based assays for allelic discrimination in maize by using the 5/-nuclease procedure. Mol Breed 2001, 8(2):169-176.

55. Olivier M: The Invader ${ }^{\circledR}$ assay for SNP genotyping. Mut Res/Fundamental Mol Mech Mut 2005, 573(1-2):103-110.

56. Wright WT, Heggarty SV, Young IS, Nicholls DP, Whittall R, Humphries SE, Graham CA: Multiplex MassARRAY spectrometry (iPLEX) produces a fast and economical test for 56 familial hypercholesterolaemia-causing mutations. Clin Genet 2008, 74(5):463-468.

57. Nijman IJ, Kuipers S, Verheul M, Guryev V, Cuppen E: A genome-wide SNP panel for mapping and association studies in the rat. BMC Genomics 2008, 9:95.

58. Sanchez JJ, Borsting C, Balogh K, Berger B, Bogus M, Butler JM, Carracedo A, Court DS, Dixon LA, Filipovic B, Fondevila M, Gill P, Harrison CD, Hohoff C, Huel R, Ludes B, Parson W, Parsons TJ, Petkovski E, Phillips C, Schmitter H, Schneider PM, Vallone PM, Morling N: Forensic typing of autosomal SNPs with a 29 SNP-multiplex-results of a collaborative EDNAP exercise. Forensic Sci Int Genet 2008, 2(3):176-183.

59. Fan JB, Oliphant A, Shen R, Kermani BG, Garcia F, Gunderson KL, Hansen M, Steemers F, Butler SL, Deloukas P, Galver L, Hunt S, McBride C, Bibikova M, Rubano T, Chen J, Wickham E, Doucet D, Chang W, Campbell D, Zhang B, Kruglyak S, Bentley D, Haas J, Rigault P, Zhou L, Stuelpnagel J, Chee MS: Highly parallel SNP genotyping. Cold Spring Harb Symp Quant Biol 2003, 68:69-78.

60. Gunderson KL: Whole-genome genotyping on bead arrays. Methods $\mathrm{Mol}$ Biol 2009, 529:197-213.

61. You F, Huo N, Deal K, Gu Y, Luo M-C, McGuire P, Dvorak J, Anderson O: Annotation-based genome-wide SNP discovery in the large and complex Aegilops tauschii genome using next-generation sequencing without a reference genome sequence. BMC Genomics 2011, 12(1):59.

62. Cloutier S, Miranda E, Ward K, Radovanovic N, Reimer E, Walichnowski A, Datla R, Rowland G, Duguid S, Ragupathy R: Simple sequence repeat marker development from bacterial artificial chromosome end sequences and expressed sequence tags of flax (Linum usitatissimum L.). Theor Appl Genet 2012, 125(4):685-694.

63. Myles S, Peiffer J, Brown PJ, Ersoz ES, Zhang Z, Costich DE, Buckler ES: Association mapping: critical considerations shift from genotyping to experimental design. Plant Cell 2009, 21(8):2194-2202.

64. Langmead B, Trapnell C, Pop M, Salzberg SL: Ultrafast and memoryefficient alignment of short DNA sequences to the human genome. Genome Biol 2009, 10(3):R25.

65. Li H, Durbin R: Fast and accurate short read alignment with BurrowsWheeler transform. Bioinformatics 2009, 25(14):1754-1760.

66. Li H, Handsaker B, Wysoker A, Fennell T, Ruan J, Homer N, Marth G, Abecasis $G$, Durbin R: The sequence alignment/map format and SAMtools. Bioinformatics 2009, 25(16):2078-2079.

67. Wang W, Wei Z, Lam T-W, Wang J: Next generation sequencing has lower sequence coverage and poorer SNP-detection capability in the regulatory regions. Science Reports 2011, doi:10.1038/srep00055.

68. Lunter G, Rocco A, Mimouni N, Heger A, Caldeira A, Hein J: Uncertainty in homology inferences: assessing and improving genomic sequence alignment. Genome Res 2008, 18(2):298-309.

69. Varala K, Swaminathan K, Li Y, Hudson ME: Rapid genotyping of soybean cultivars using high throughput sequencing. PLOS One 2011, 6(9):e24811.

70. Elshire RJ, Glaubitz JC, Sun Q, Poland JA, Kawamoto K, Buckler ES, Mitchell SE: A robust, simple genotyping-by-sequencing (GBS) approach for high diversity species. PLOS One 2011, 6(5):e19379.

71. Simko I, Haynes KG, Jones RW: Assessment of linkage disequilibrium in potato genome with single nucleotide polymorphism markers. Genetics 2006, 173(4):2237-2245.

72. Barker GL, Edwards KJ: A genome-wide analysis of single nucleotide polymorphism diversity in the world's major cereal crops. Plant Biotechnol J 2009, 7(4):318-325.

73. Velasco R, Zharkikh A, Troggio M, Cartwright DA, Cestaro A, Pruss D, Pindo M, Fitzgerald LM, Vezzulli S, Reid J, Malacarne G, lliev D, Coppola G, Wardell B, Micheletti D, Macalma T, Facci M, Mitchell JT, Perazzolli M, Eldredge G, Gatto P, Oyzerski R, Moretto M, Gutin N, Stefanini M, Chen Y, Segala C, 
Davenport C, Dematte L, Mraz A, et al: A high quality draft consensus sequence of the genome of a heterozygous grapevine variety. PLoS One 2007, 2(12):e1326.

74. Van Deynze A, Stoffel K, Buell CR, Kozik A, Liu J, van der Knaap E, Francis D: Diversity in conserved genes in tomato. BMC Genomics 2007, 8:465.

75. J-k J, Park S-W, Liu W, Kang B-C: Discovery of single nucleotide polymorphism in Capsicum and SNP markers for cultivar identification. Euphytica 2010, 175(1):91-107.

76. Guo X, Wang Y, Keightley PD, Fan L: Patterns of selective constraints in noncoding DNA of rice. BMC Evol Biol 2007, 7:208.

77. Salvi S, Sponza G, Morgante M, Tomes D, Niu X, Fengler KA, Meeley R, Ananiev EV, Svitashev S, Bruggemann E, Li B, Hainey CF, Radovic S, Zaina G, Rafalski JA, Tingey SV, Miao G-H, Phillips RL, Tuberosa R: Conserved noncoding genomic sequences associated with a flowering-time quantitative trait locus in maize. Proc Natl Acad Sci USA 2007, 104(27):11376-11381.

78. Yang Z, Yoder AD: Estimation of the transition/transversion rate bias and species sampling. J Mol Evol 1999, 48(3):274-283.

79. Rowland GG, Hormis YA, Rashid KY: CDC Bethune flax. Can J Plant Sci 2002, 82(1):101-102

80. Duguid SD, Kenaschuk EO, Rashid KY: Macbeth flax. Can J Plant Sci 2003, 83(4):803-805.

81. Dribnenki JCP, McEachern SF, Chen Y, Green AG, Rashid KY: Linola ${ }^{\mathrm{TM}} 2047$ low linolenic flax. Can J Plant Sci 2003, 83(1):81-83.

82. Åkerman Å, Nilsson F, Sylvén N, Fröier K: Svensk växtförädling. Del 1 Åkerbruksväxterna. (Plant Breeding in Sweden. I. Field Crops). Stockholm: Natur och kultur; 1951:745.

83. Bennett S: Solexa Ltd. Pharmacogenomics 2004, 5(4):433-438.

84. Stanke M, Diekhans M, Baertsch R, Haussler D: Using native and syntenically mapped CDNA alignments to improve de novo gene finding. Bioinformatics 2008, 24(5):637-644.

85. Majoros WH, Pertea M, Salzberg SL: TigrScan and GlimmerHMM: two open source $a b$ initio eukaryotic gene-finders. Bioinformatics 2004, 20(16):2878-2879.

doi:10.1186/1471-2164-13-684

Cite this article as: Kumar et al:: Genome wide SNP discovery in flax through next generation sequencing of reduced representation libraries. BMC Genomics 2012 13:684.

\section{Submit your next manuscript to BioMed Central and take full advantage of:}

- Convenient online submission

- Thorough peer review

- No space constraints or color figure charges

- Immediate publication on acceptance

- Inclusion in PubMed, CAS, Scopus and Google Scholar

- Research which is freely available for redistribution 